\title{
Effect of Temperature on the Corrosion Behaviour of Al-12Si-1Mg Automotive Alloy in 3.5\% NaCl Solution
}

\author{
M. S. Kaiser* \\ Directorate of Advisory, Extension and Research Services, Bangladesh University of Engineering and \\ Technology, Dhaka-1000, Bangladesh. \\ * Corresponding author. Tel.: +88-02-9663129; email: mskaiser@iat.buet.ac.bd \\ Manuscript submitted December 27, 2016; accepted March 24, 2017. \\ doi: 10.17706/ijmse.2017.5.2.87-94
}

\begin{abstract}
The effect of temperature on the corrosion behavior of Al-12Si-1Mg automotive alloy in $3.5 \% \mathrm{NaCl}$ solution was studied. The work was carried out using conventional gravimetric measurements and complemented by resistivity, optical micrograph, scanning electron microscopy (SEM) and X-ray analyzer (EDX) investigations. Gravimetric analysis confirmed that with varying exposure periods by both the environment the weight loss of the alloy increases and the normal corrosion rate profile of an initial steep rise followed by a nearly constant value of corrosion rate were observed. The rate of corrosion at room temperature of the alloy was found to be lower than that of higher temperature solution. At higher solution temperature attack of corrodent on surface is increased due to higher rate of chemical reactions. Optical micrographs of the alloy show the higher pit density at higher solution temperature.
\end{abstract}

Keywords: Al-Si alloys, $\mathrm{NaCl}$ solution, heat, corrosion, gravimetric analysis, SEM.

\section{Introduction}

Al-Si based casting alloys have been widely used in automobile. In recent years, the understanding of eutectic solidification in Al-Si based casting alloys has drawn a great attention to many researchers [1]-[3]. Materials for lightweight construction in automotive engineering must meet complex requirements. It is essential to combine good formability with high strength in service, excellent corrosion resistance and weldability [4]. For automotive body panels, additional decorative requirements must be met, which require a perfect material surface. Corrosion is a natural process, which converts a refined metal to a more chemically-stable form, such as its oxide, hydroxide, or sulfide and chloride. It is the gradual destruction of materials by chemical and/or electrochemical reaction with their environment [5]. Corrosion behaviour of aluminum alloys is significantly affected by the presence of particles in the matrix [6]. Particles that contain $\mathrm{Cu}$ and $\mathrm{Mg}$ tend to be anodic relative to the alloy matrix, while those that contain Fe and Mn behave in cathodic manner relative to the matrix [7]. Previous works show that $\mathrm{Mg}_{2} \mathrm{Si}$ particles tend to be anodic in relation to the matrix and can act as initiation sites for corrosion [8], [9]. Most often the $\mathrm{Mg}_{2} \mathrm{Si}$ phase dissolves leaving behind a cavity, which acts as a nucleation site for pitting [10]. These observations were made during investigations that were carried out on commercial aluminum alloys having low $\mathrm{Si} / \mathrm{Mg}$ molar ratios [11]. There are many factors that influence the corrosion of metal namely oxygen, temperature, chemical salts, humidity, pollutants etc. Among the different factors affecting the corrosion rate, the temperature plays an important role [12], [13]. Increasing temperature leads to change two variables that act in a conflicting way. Firstly, increasing temperature accelerates the reaction rate and diffusion rate of oxygen 
species by increasing the molecular diffusion coefficient. Secondly, as the temperature increases the oxygen solubility decreases [14].

The aim of the present study was to studying the effect of temperature on the corrosion behavior of aged Al-12Si-1Mg automotive alloy in 3.5\% NaCl solution. The research has been directed towards studying the characteristics, condition of formation and morphology of attack. The corrosion data was taken after 47 days immersion in the solution and was investigated using weight-loss data and complemented by SEM/EDX investigations.

\section{Experimental Details}

Commercially used aluminium pistons were melted in a clay-graphite crucible under the suitable flux cover (degasser, borax etc.). The final temperature of the melt was always maintained at $750 \pm 15^{\circ} \mathrm{C}$. Casting was done in cast iron metal moulds preheated to $200^{\circ} \mathrm{C}$. Mould sizes were 16 × 150 x 300 in millimeter. The alloy was analysed by wet chemical and spectrochemical methods simultaneously. The chemical composition of the alloy is given in Table 1 . The cast alloy was homogenized in a Muffle furnace at $400^{\circ} \mathrm{C}$ for 18 hours and air cooled to relieve internal stresses and for homogenization. The homogenized samples was solutionized at $530^{\circ} \mathrm{C}$ for 2 hours followed by salt ice water quenching to get a super saturated single phase region. The samples of $50 \times 16 \times 3 \mathrm{~mm}^{3}$ size obtained and were artificially aged at $225^{\circ} \mathrm{C}$ for 90 minutes to conduct the tests for studying the corrosion behaviour. The samples were wet-sanded mechanically with SiC papers of 220 and 1200 grit. Before use, the samples were de-greased with ethanol of $99 \%$ purity and then rinsed with plenty of water. Afterwards, they were dried, weighted (initial) different exposure periods up to 47 days. A stagnant solution of $3.5 \% \mathrm{NaCl}$ at $\mathrm{pH} 5.5$ was used as the aggressive medium. Solution was prepared by dissolving $3.5 \pm 0.1$ parts by weight $\mathrm{NaCl}$ in $96.5 \pm 0.1$ parts of distilled water. One solution was used at room temperature and another was heated at $80^{\circ} \mathrm{C}$ per day. After the designated exposure in the solution medium, the samples were rinsed with distilled water, dried between two tissue papers, and weighted again (final weight, $\mathrm{W}_{\text {fin }}$ ). Weight-loss measurements were made in triplicate and weight loss was calculated by taking an average of these values [15].

$$
\begin{aligned}
& \text { Weight loss: } \Delta W=\frac{\left(W_{\text {int }}-W_{f i n}\right)}{A} \\
& \text { Corrosion Rate: } K_{\text {Corr }}=\frac{(K \times \Delta W)}{(A \times T \times D)}
\end{aligned}
$$

Where,

$\mathrm{W}_{\text {int }}=$ initial weight before immersion

$\mathrm{W}_{\text {fin }}=$ final weight after exposure

$\mathrm{K}=$ unit conversion constant $\left(\mathrm{K}=8.76 \times 10^{4}\right.$ for the mmpy unit $)$

$\mathrm{T}=$ time of exposure (hrs)

$\mathrm{A}=$ area in $\left(\mathrm{cm}^{2}\right)$,

$\Delta \mathrm{W}=$ Weight loss $(\mathrm{g})$

and $\mathrm{D}=$ density of metal $\left(\mathrm{g} / \mathrm{cm}^{3}\right)$

Electrical conductivity of the alloy at different condition was carried out with an Electric Conductivity Meter, type 979. Electric resistivity was calculated from those conductivity data. The washed and dried samples were observed carefully in OPTIKA Microscope and some selected photomicrographs were taken. The SEM investigation and EDX analysis were obtained for the surface of the alloy specimens after their immersions 
in the solution medium for 47 days. The SEM images were collected by using a JEOL scanning electron microscope with an energy dispersive X-ray analyzer (Model: Link AN - 10000) attached.

Table 1. Chemical Composition of the Experimental Alloy (wt\%)

\begin{tabular}{cccccccccc}
\hline \hline & $\mathrm{Si}$ & $\mathrm{Mg}$ & $\mathrm{Cu}$ & $\mathrm{Ni}$ & $\mathrm{Fe}$ & $\mathrm{Mn}$ & $\mathrm{Ti}$ & $\mathrm{Zn}$ & $\mathrm{Al}$ \\
\hline Alloy & 12.280 & 0.919 & 1.120 & 1.306 & 0.521 & 0.038 & 0.061 & 0.081 & $\mathrm{Bal}$ \\
\hline \hline
\end{tabular}

\section{Results and Discussion}

\subsection{Gravimetric Analysis}

Fig. 1 depicts the change of weight loss $\Delta \mathrm{W}, \mathrm{mg} \mathrm{cm}^{-2}$, calculated using (1) as a function of immersion time for $\mathrm{Al}-12 \mathrm{Si}-1 \mathrm{Mg}$ automotive alloy in $3.5 \% \mathrm{NaCl}$ solution at room temperature and solution heated at $80^{\circ} \mathrm{C}$ for 3 hours per day simultaneously. It is observed that weight loss was more predominant at higher temperature solution in comparison to room temperature. In case of room temperature solution at initial stage it is found to weight gain as the sample had negative corrosion rates. The weight gain is as a result of the formation of passive films on the surface of the samples which lead to the temporary seizure of the corrosion attack. Corrosion attack is restored after some days as is observed from Fig. 1 due to the gradual breakdown of the passive films. For higher temperature solution corrosion reaction increased and the diffusion of corrosion species are accelerated which the causes the higher weight loss. The values of $\mathrm{K}_{\text {corr }}$, which were calculated from weight-loss tests using (2) for the alloy, are plotted against time as shown in Fig. 2. It can be seen that, the $\mathrm{K}_{\text {Corr }}$ values increased quite abruptly initially until immersion time of 10 days. Afterwards, the $\mathrm{K}_{\text {Corr }}$ value and attained roughly a constant value with immersion time. Corrosion rates increase at higher solution temperature. For most chemical reactions, the reaction rate increases with increasing temperature. Temperature affects the corrosion rate of metals in electrolytes primary through its effect on factors which control the diffusion rate of oxygen. Temperature affects the corrosion rate by virtue of its effect on the oxygen solubility and oxygen diffusion coefficient. As temperature increases the diffusion coefficient of oxygen also increases which tends to increase the corrosion rate [16]. At higher days of exposure the accumulation of corrosion products including aluminium oxide and hydroxide, which cover up the surface leading to decrease the weight loss and the uniform weight loss causes the constant corrosion rate.

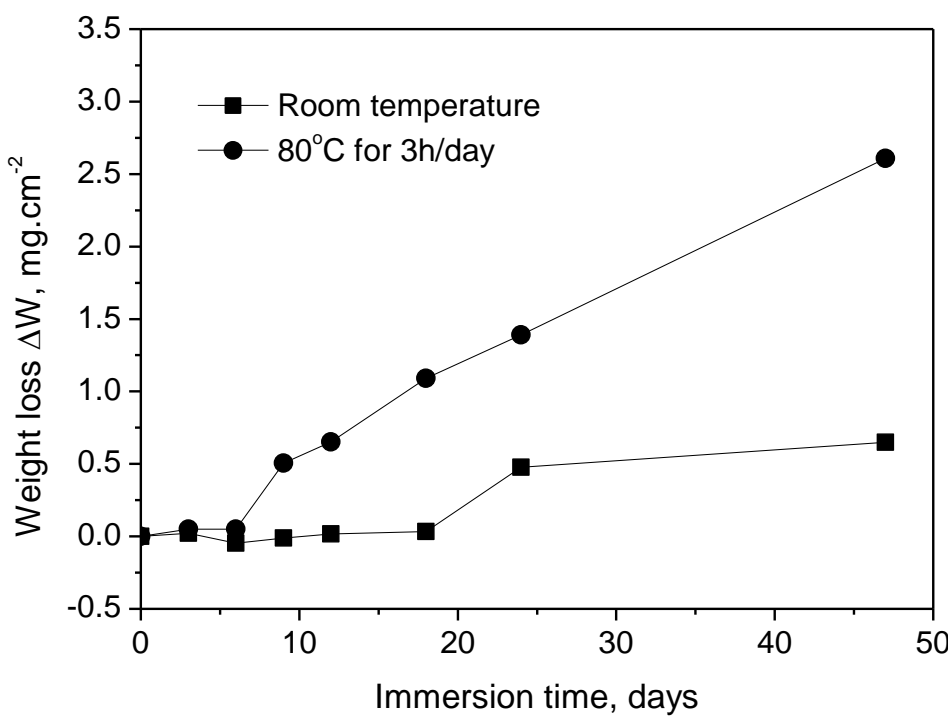

Fig. 1. The variation of the weight loss as a function of immersion time for Al-12Si-1Mg automotive alloy immersed at room temperature and heated $80^{\circ} \mathrm{C}$ for 3 hours per day in $3.5 \% \mathrm{NaCl}$ solution. 


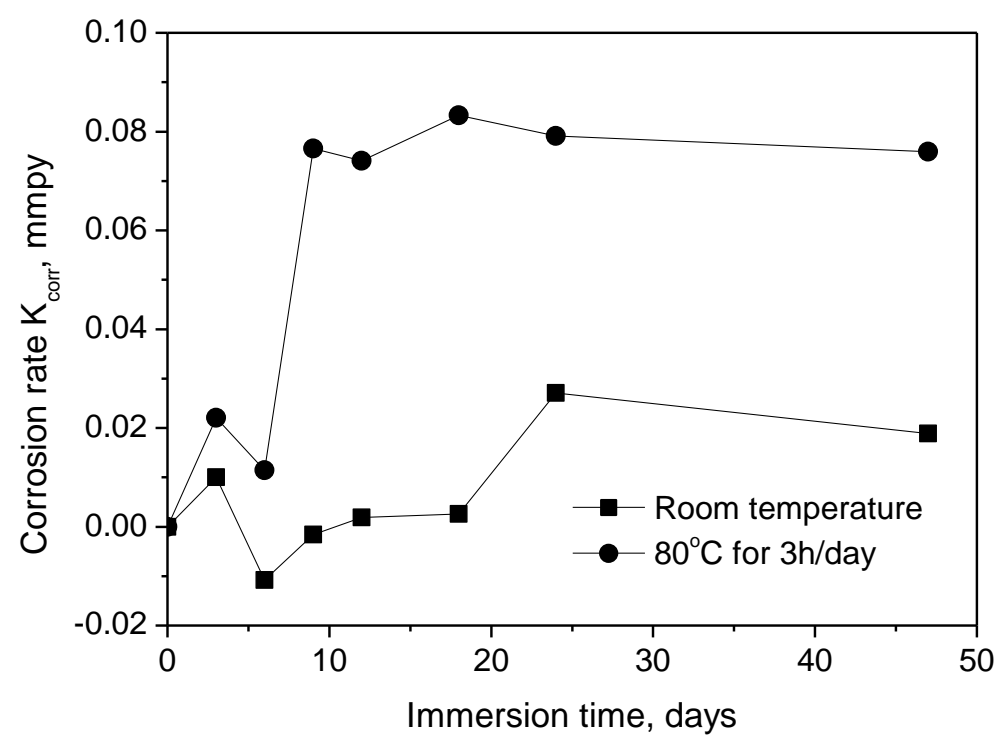

Fig. 2. The change of corrosion rate as a function of immersion time for Al-12Si-1Mg automotive alloy immersed at room temperature and heated $80^{\circ} \mathrm{C}$ for 3 hours per day in $3.5 \% \mathrm{NaCl}$ solution.

\subsection{Electrical Resistivity Analysis}

The resistivity values of the alloy immersed in $3.5 \% \mathrm{NaCl}$ solution for 47 days at room temperature shows a general trend of decrease (Fig. 3). This is due to the fact that it corrodes very quickly. Aluminum forms a very thin film of aluminum oxide and hydroxide which is about $2 \mathrm{~nm}$ thick and it has a bond to its surface which affects the resistivity. In case of heated solution the resistivity of the alloy increases slightly with immersion time. It is due to fact that the increasing temperature accelerates the reaction rate and gradual breakdown of the passive films [17]. Higher pit formation produces an uneven surface which increases the electrical resistivity of the surface of the experimental alloy.

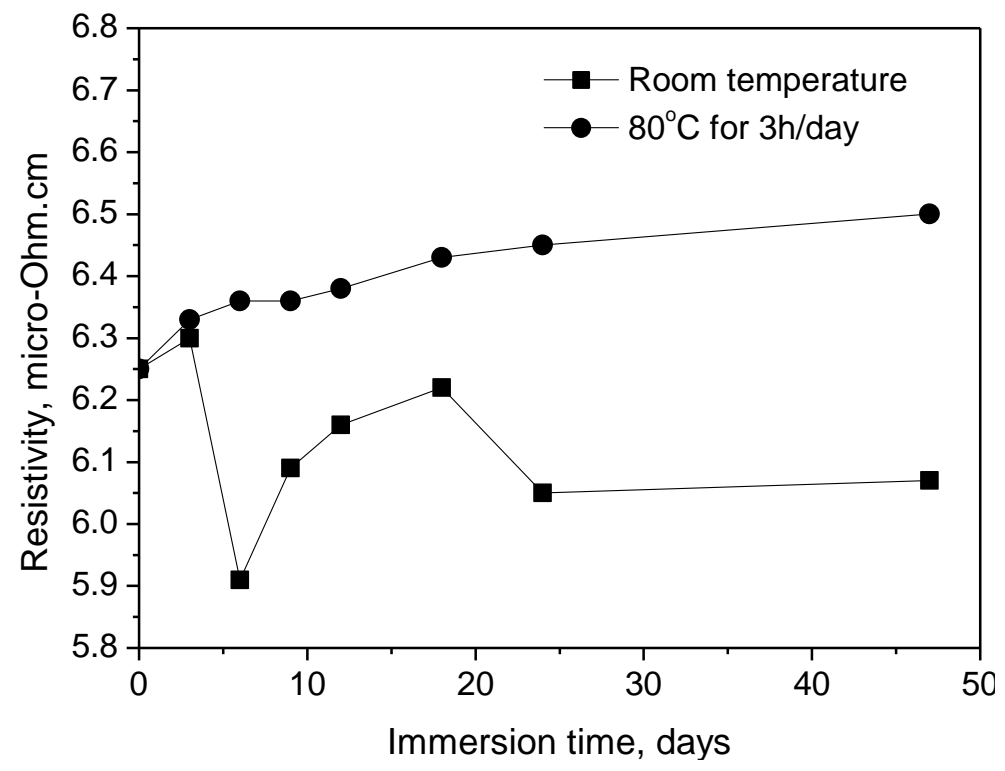

Fig. 3. The change of resistivity as a function of immersion time for Al-12Si-1Mg automotive alloy immersed at room temperature and heated $80^{\circ} \mathrm{C}$ for 3 hours per day in $3.5 \% \mathrm{NaCl}$ solution. 


\subsection{Optical Micrographic Observation}

Fig. 4a shows the optical micrograph of polished Al-12Si-1Mg automotive alloy before immersion into the corrosion medium. The samples has a microstructure characterized by an Al-rich dendritic matrix, $\alpha$-Al phase and a eutectic mixture in the interdendritic region formed by silicon particles, which are coarse and distributed in plate-like morrphology, set in an Al-rich phase [18]. In this type of image the precipitates of $\mathrm{Al}(\mathrm{Mn}, \mathrm{Fe}, \mathrm{Cu})$ are those that appear in the dark tone while those of $\mathrm{Al}(\mathrm{Si}, \mathrm{Mg})$ appear in a lighter tone. In Fig. $4 \mathrm{~b}$ and $4 \mathrm{c}$ are seen that after removing the samples from the $3.5 \% \mathrm{NaCl}$ solution at room temperature and heated solution at $80^{\circ} \mathrm{C}$ for 3 hours per day for 47 days respectively, severe corrosion was observed. These findings primarily suggested that $3.5 \% \mathrm{NaCl}$ can be an aggressive medium to induce corrosion in the aluminium alloys. At room temperatures corrodent attack on surface is less due to less water temperature. It results into low pit density. At higher solution temperature, pit depth is found to be increasing due to availability of air. With increase in water temperature attack of corrodent on surface is increased. This leads to more pit density at higher solution temperatures.

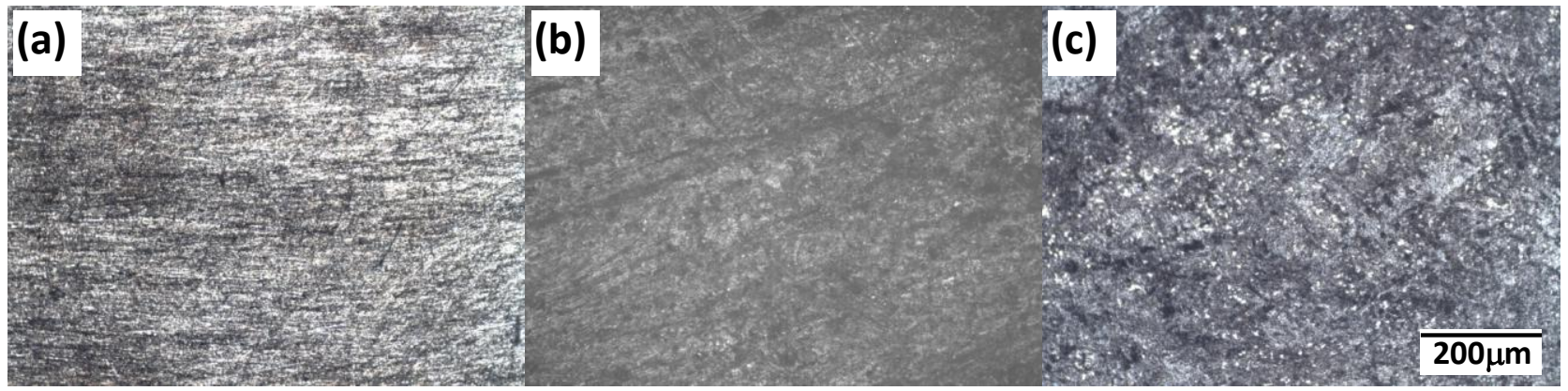

Fig. 4. Microstructure of Al-12Si-1Mg automotive alloy a) polished before corrosion b) after corrosion in $3.5 \% \mathrm{NaCl}$ solution for 47 days c) after corrosion in $3.5 \% \mathrm{NaCl}$ solution for 47 days heated at $80^{\circ} \mathrm{C}$ for 3 hours per day.

\subsection{SEM Observation}

The SEM images of the Al-12Si-1Mg automotive alloy after 47 days of prolonged exposure in $3.5 \% \mathrm{NaCl}$ solution at room temperature and heated solution at $80^{\circ} \mathrm{C}$ for $3 \mathrm{~h}$ per day as shown in Fig. $5 \mathrm{a}$ and $5 \mathrm{~b}$ respectively. The microstructures are characterized by $\alpha-\mathrm{Al}$ matrix, eutectic $\mathrm{Si}, \mathrm{Al}_{15}(\mathrm{Fe}, \mathrm{Mn})_{3} \mathrm{Si}_{2}$ intermetallic [19]. They indicate that the surfaces compose of thin corrosion products from which the mushrooms were formed and the other area is covered with a thin layer of corrosion products. The higher intensity of corrosion is observed in the alloy which immersed in hot solution. Most chemical reactions do go faster the higher the temperature. All atoms and molecules are moving all the time. So increasing the temperature causes them to move faster and that increases most chemical reactions [20,21]. The weight percentage of elements found by EDX analysis in the selected area of the SEM are $40.21 \% 0,0.54 \% \mathrm{Na}, 1.36 \% \mathrm{Mg}, 23.52 \%$ $\mathrm{Al}, 30.32 \% \mathrm{Si}, 0.27 \% \mathrm{Cl}, 1.13 \% \mathrm{Mn}, 0.53 \% \mathrm{Fe}, 0.01 \% \mathrm{Ni}, 0.99 \% \mathrm{Cu}$ and $1.12 \% \mathrm{Zn}$ for the alloy at room temperature solution.

The weight percentage of elements found by EDX analysis in the selected area of the SEM for the alloy at higher temperature solution are $42.98 \% 0,1.04 \% \mathrm{Na}, 1.47 \% \mathrm{Mg}, 14.61 \% \mathrm{Al}, 34.11 \% \mathrm{Si}, 0.18 \% \mathrm{Cl}, 2.07 \mathrm{Mn}$, $0.15 \% \mathrm{Fe}, 0.36 \% \mathrm{Ni}, 1.29 \% \mathrm{Cu}$ and $1.75 \% \mathrm{Zn}$. From the analysis it is shown that higher temperature solution accelerates the chemical reaction and formation of higher passive films on the surface. 

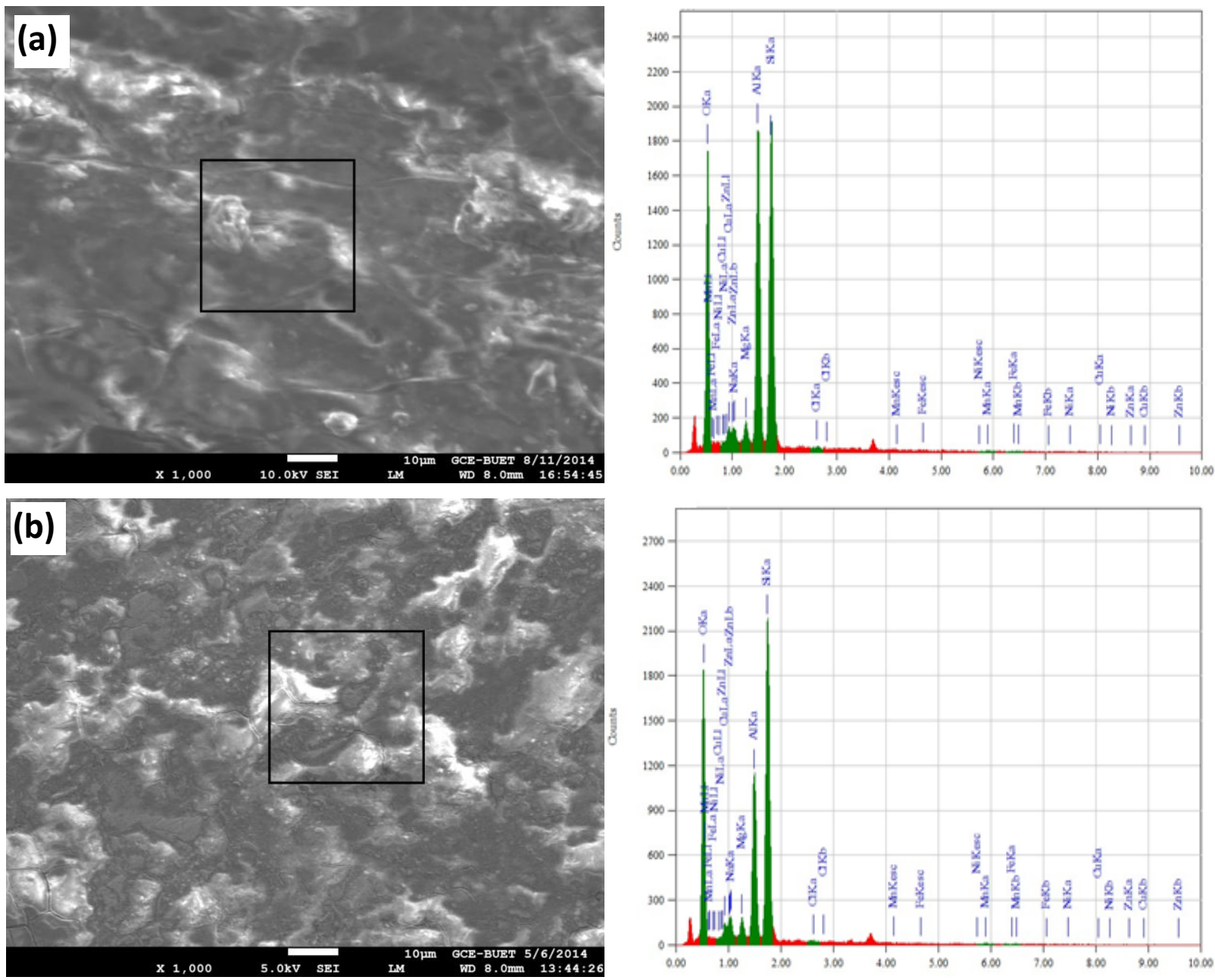

Fig. 5. SEM images of Al-12Si-1 Mg automotive alloy after exposure in a $3.5 \% \mathrm{NaCl}$ solution for 47 days.

a) room temperature and b) heated at $80^{\circ} \mathrm{C}$ for $3 \mathrm{~h}$ per day.

\section{Conclusion}

The results obtained indicate that the heated solution of $3.5 \% \mathrm{NaCl}$ affected on corrosion and increases its corrosion rate of $\mathrm{Al}-12 \mathrm{Si}-1 \mathrm{Mg}$ automotive alloy. At room temperature the alloy showed better corrosion behavior. Corrosion weight loss increases at higher temperature due to higher rate of chemical reactions. Temperature affects the corrosion rate of $\mathrm{Al}-12 \mathrm{Si}-1 \mathrm{Mg}$ automotive alloy because of it accelerates the reaction rate and diffusion rate of oxygen and decreases of oxygen solubility. The gradual breakdown of the passive films leads to more pit density at higher solution temperature. Higher pit formation produces an uneven surface which increases the electrical resistivity of the experimental alloy.

\section{Acknowledgment}

This work is part of the project "Effect of trace zirconium on the chemical, electrical, mechanical and physical properties of cast and heat treated aluminium-silicon piston alloy", which is supported by CASR of Bangladesh University of Engineering and Technology. Thanks to Department of Glass and Ceramics Engineering for providing the laboratory facilities. 


\section{References}

[1] Liao, H. C., Zhang, M., Bi, J. J., Ding, K., Xi , X. \& Wu, S. Q. (2010). Eutectic solidification in near-eutectic Al-Si casting alloys. J. Mater. Sci. Technol, 26(12), 1089-1097.

[2] Osorio, W. R., Cheung, N., Spinelli, J. E., Goulart, P. R. \& Garcia, A. (2007). The effects of a eutectic modifier on microstructure and surface corrosion behavior of Al-Si hypoeutectic alloys. Journal of Solid State Electrochemistry, 11(10), 1421-1427.

[3] Garrigues, L., Pebere, N., \& Dabosi, F. (1996) An investigation of the corrosion inhibition of pure aluminum in neutral and acidic chloride solutions. Electrochimica Acta, 41(7-8), 1209-1215.

[4] Kaiser, M. S., \& Dutta, S. (2014). Comparison of corrosion behaviour of commercial aluminium engine block and piston in 3.5\% NaCl solution. International Journal of Advances in Materials Science and Engineering, 1(1), 9-17.

[5] Syed, S. (2006). Atmospheric corrosion of metals. Emirates Journal for Engineering Research, 11(1), 1-24.

[6] Loto, R. T., \& Adeleke, A. (2016). Corrosion of aluminum alloy metal matrix composites in neutral chloride solutions. Journal of Failure Analysis and Prevention, 16(15), 874-885.

[7] Wei, R. P., Liao, C. M., \& Gao, M. (1998). A transmission electron microscopy study of constituent-particle-induced corrosion in 7075-T6 and 2024-T3 aluminum alloys. Metallurgical and Materials Transactions A, 29(4), 1153-1160.

[8] Yasakau, K. A., Zheludkevich, M. L., Lamaka, S. V., \& Ferreira, M. G. S. (2007). Role of intermetallic phases in localized corrosion of AA5083. Electrochimica Acta, 52(27), 7651-7659.

[9] De Wit, J. H. W. (2004). Local potential measurements with the SKPFM on aluminium alloys. Electrochimica Acta, 49(17-18), 2841-2850.

[10] Birbilis, N., \& Buchheit, R. G. (2005). Electrochemical characteristics of intermetallic phases in aluminum alloys : an experimental survey and discussion. Journal of the Electrochemical Society, 152(4), 140-151.

[11] Shreir, L. L. (2000). Corrosion Handbook (3rd ed.). London: Newnes-Butter.

[12] Malik, M. A., Hashim, M. A., Nabi, F., Althabaiti, S. A., \& Khan, Z. (2011). Anti-corrosion ability of surfactants: A review. Int. J. Electrochem. Sci., 6, 1927-1948.

[13] Huang, W. E., \& Buchheit, R. G. (2015). Uniform corrosion dependence on temperature and pH of aluminum alloys 2024-T3. ECS Transactions, 66(17), 97-107.

[14] Sherif, E. M. (2012). Corrosion behavior of magnesium in naturally aerated stagnant seawater and 3.5\% sodium chloride solutions. Int. J. Electrochem. Sci., 7, 4235-4249.

[15] Strehblow, H. H. (1995). Corrosion mechanism in theory and practice. New York: Marcel Dekker.

[16] Alaneme, K. (2011). Corrosion behaviour of heat-treated Al-6063/ SiCp composites immersed in $5 \mathrm{wt} \%$ $\mathrm{NaCl}$ solution. Leonardo Journal of Sciences, 18, 55-64.

[17] Rodríguez, D. R. A., Uruchurtu, C. J., Cotero, V. A. M., Valdez, S., \& Juárez, I. J. A. (2015). Corrosion behavior of AlMgSi alloy in aqueous saline solution. Int. J. Electrochem. Sci., 10, 1792-1808.

[18] Osorio, W. R., Cheung, N., Peixoto, L. C. and Garcia, A. (2009). Corrosion resistance and mechanical properties of an $\mathrm{Al} 9 \mathrm{wt} \% \mathrm{Si}$ alloy treated by laser surface remelting. Int. J. Electrochem. Sci., 4, 820 - 831.

[19] Bidmeshki, C., Abouei, V., Saghafian, H., Shabestari, S. G. and Noghani, M. T. (2016). Effect of Mn addition on Fe-rich intermetallics morphology and dry sliding wear investigation of hypereutectic $\mathrm{Al}-17.5 \% \mathrm{Si}$ alloys. Journal of Materials Research and Technology, 5(3), 250-258.

[20] Hackerman, N. (1952). Effect of temperature on corrosion of metals by water. Industrial and Engineering Chemistry, 44(8), 1752-1755.

[21] Khadom, A. A., Yaro, A. S., Kadum, A. A. H., Altaie, A. S., \& Musa, A. Y. (2009). The effect of temperature and acid concentration on corrosion of low carbon steel in hydrochloric acid media. American Journal of Applied Sciences, 6 (7), 1403-1409. 


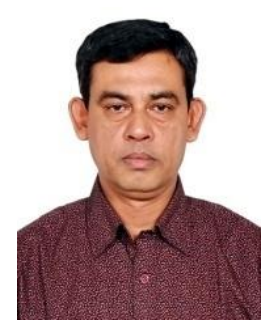

Md. Salim Kaiser was born in Jhenaidah, Bangladesh on November 01, 1962. He received his Graduation degree in Mechanical Engineering from Institution of Engineers, Bangladesh, in 1990, PGD in Industrial Management from Bangladesh Management Development Center, Dhaka, in 1992, the M. Engg. degree in optics from BIT Khulna, Bangladesh, in 2000 and the Ph.D. degree in Material science from Bengal Engineering and Science University, Shibpur, India, in 2005. He also worked as a post doctoral fellow, School of Materials Science \& Engineering of Bengal Engineering and Science University in 2012. His research interests include materials science engineering, physics and astronomy. At present, he is working as Deputy Director, Directorate of Advisory, Extension and Research Services, Bangladesh University of Engineering and Technology, Dhaka. Dr. Kaiser is a fellow of Engineers Institution Bangladesh (IEB) and Bangladesh Computer Society (BCS). 